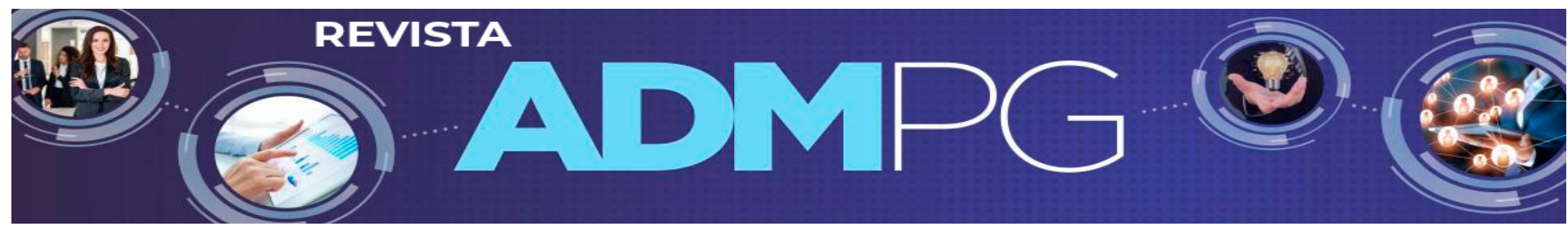

DOI: 10.5212/Admpg.v.11.18482.001

ISSN: 1983-7089

\title{
DESAFIOS DA PRIMEIRA EXPORTAÇÃO PARA O MICRO E PEQUENO EMPREENDEDOR: UMA PESQUISA QUALITATIVA COM EMPRESAS QUE PARTICIPARAM DO PROGRAMA DE QUALIFICAÇÃO PEIEX-FECAP (2018-2020)
}

\author{
CHALLENGES OF THE FIRST EXPORT FOR MICRO AND SMALL ENTREPRENEURS: A QUALITATIVE SURVEY WITH \\ COMPANIES THAT PARTICIPATED IN THE PEIEX-FECAP QUALIFICATION PROGRAM (2018-2020)
}

DESAFÍOS DE LA PRIMERA EXPORTACIÓN PARA MICRO Y PEQUEÑOS EMPRENDEDORES: ENCUESTA CUALITATIVA A EMPRESAS QUE PARTICIPARON EN EL PROGRAMA DE CALIFICACIÓN PEIEX-FECAP (2018-2020)

\section{Alexandre de Souza Pereira ${ }^{1}$ Jésus de Lisboa Gomes ${ }^{2}$ Mirian Pires Eustachio de Medeiros Vale ${ }^{3}$}

\section{RESUMO}

No Brasil, existem 6,4 milhões de estabelecimentos. Desse total, 99\% são Micro e Pequenas Empresas (MPEs), representando mais de $52 \%$ de todos os empregos formais no Brasil. Porém, quando o assunto é exportação, existem pouco mais de nove mil empresas exportadoras, segundo dados do Sebrae, 2018. Em termos de valores médios, a participação se torna inexpressiva. Mesmo sabendo sobre os benefícios desta prática, sua participação na exportação é considerada pouco significativa. As MPEs constituem uma parcela importante da geração de emprego e receita no país, ainda que enfrentando dificuldades. Assim, esta pesquisa buscou identificar os desafios da primeira exportação para o micro e pequeno empreendedor. Foi realizada uma pesquisa qualitativa com empresas participantes do programa de qualificação para exportação (PEIEX) que foi levado a cabo pela Fundação Escola de Comércio Álvares Penteado (FECAP) entre os anos de 2018 e 2020. Por meio de entrevistas semisestruturadas analisadas pela técnica da Análise de Conteúdo, foram observados sete desafios categorizados nesse estudo; em destaque, estão os desafios de gestão, processual e marketing. Conclui-se que é preciso atentar à necessidade de programas de formação, fomento e apoio às MPEs, assim como a prática de novas tecnologias que facilitem e estimulem estas empresas à exportação.

Palavras Chave: Primeira exportação, Programa de qualificação para exportação, Micro e Pequena Empresa, Desafios.

\begin{abstract}
The objective of this study is to describe, in a comparative way, the level of budgetary and accounting disclosure In Brazil there are 6.4 million establishments, of which 99\% are Micro and Small Enterprises (SMEs), representing just over $52 \%$ of all formal jobs in Brazil. However, when it comes to exports, there are just over nine thousand exporting companies, according to data from Sebrae, 2018. In terms of average values, the participation becomes insignificant. Even though the benefits of this practice are known, their participation in exports is considered to be insignificant. SMEs are an important part of the generation of jobs and income in the country, although they face difficulties. Thus, this research aims to identify the challenges of the first export for micro and small entrepreneurs. A qualitative research was carried out with companies participating in the export qualification program (PEIEX) that was carried out by the Fundação Escola de Comércio Álvares Penteado (FECAP) between the years 2018 and 2020. Through semi-structured interviews analyzed by the technique of Content Analysis, it was observed seven challenges categorized in this study; highlighted, are the management, procedural and marketing challenges. It is concluded that it is necessary to pay attention to the need for training, promotion and support programs for SMEs, as well as the practice of new technologies that facilitate and encourage these companies to export.
\end{abstract}

Keywords: First Exportation, Qualification Exportation Programs, Micro and Small Business, Challenges.

\section{RESUMEN}

En Brasil hay 6,4 millones de establecimientos, de los cuales el 99\% son Micro y Pequeñas Empresas (PYMES), lo que representa poco más del $52 \%$ de todos los empleos formales en Brasil. Sin embargo, en lo que respecta a las exportaciones, hay algo más de nueve mil empresas exportadoras, según datos de Sebrae, 2018. En términos de valores promedio, la participación se vuelve insignificante. Si bien se conocen los beneficios de esta práctica, su participación en las exportaciones se considera insignificante. Las pymes son una parte importante de la

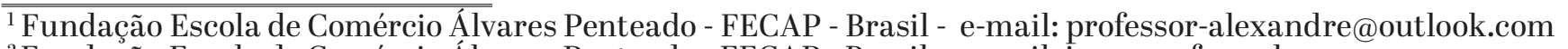
${ }^{2}$ Fundação Escola de Comércio Álvares Penteado - FECAP - Brasil - e-mail: jgomes@fecap.br

${ }^{3}$ Fundação Escola de Comércio Álvares Penteado - FECAP - Brasil - e-mail: vale@fecap.br

Revista ADMPG, Ponta Grossa, v. 11, e2118482, p. 1- 17, 2021. 
generación de empleo e ingresos en el país, aunque enfrentan dificultades. Así, esta investigación tiene como objetivo identificar los desafíos de la primera exportación para micro y pequeños empresarios. Se realizó una investigación cualitativa con empresas participantes en el programa de calificación de exportaciones (PEIEX) que fue realizado por la Fundação Escola de Comércio Álvares Penteado (FECAP) entre los años 2018 y 2020. A través de entrevistas semiestructuradas analizadas por la técnica de Contenidos En el análisis, se observaron siete desafíos categorizados en este estudio; destacan los desafíos de gestión, procedimientos y marketing. Se concluye que es necesario prestar atención a la necesidad de programas de formación, promoción y apoyo a las PYMES, así como a la práctica de nuevas tecnologías que faciliten y animen a estas empresas a exportar.

Palabras Clave: Primera Exportación, Programas de exportación de calificaciones, Micro y pequeñas empresas, Desafíos

\section{INTRODUÇÃ̃O}

Ao longo dos anos, diferentes medidas de expansão têm sido desenvolvidas ou aplicadas dentro das empresas, visando apresentar seus produtos ou serviços em uma maior área possível. A exportação pode ser considerada uma atividade impulsionadora para o crescimento econômico e financeiro da empresa e do país, ainda que exija determinados cuidados por parte dos seus gestores ou administradores, dado os desafios em obter informações do mercado alvo ou mesmo em contratar e negociar com intermediários e representantes (Davidson \& Harrigan, 1977; Sallenave, 1977; Tookey, 1975).

Um dos setores de forte relevância socioeconômica para o país é o de Micro e Pequenas Empresas (MPEs). No Brasil, existem 6,4 milhões de estabelecimentos dos quais 99\% são MPEs, responsáveis por mais de 16,1 milhões de empregos que representam em torno de 52\% de todos os trabalhos formais no país (Serviço Brasileiro de Apoio às Micro e Pequenas Empresas [Sebrae], 2018). Por outro lado, quanto ao potencial de geração de riqueza, é menor a proporção das MPEs no Produto Interno Bruto (PIB), com um valor na ordem de 21\% (Faria \& Simeone, 2019; Gomes, Silveira, \& Amal, 2010; Sebrae, 2018).

Em relação ao mercado internacional, em termos de volume, houve pouco mais de nove mil MPEs exportadoras ativas, uma participação de 38\% de todo o volume nacional exportado (Sebrae, 2018). Contudo, quando analisados os valores médios exportados em dólar, a participação é inexpressiva (Sebrae, 2018).

Em geral, as MPEs concentram seus esforços de exportação em poucos mercados no exterior. Pesquisa realizada pelo Sebrae constata que as micro e pequenas empresas brasileiras, no ano de 2017, escolheram principalmente os mercados localizados na América Latina, isto é, nações pertencentes ao Mercosul (Sebrae, 2018).

O interesse em exportar pode ocorrer por diversas razões. Algumas empresas veem o câmbio como uma vantagem, enquanto outras buscam o mercado internacional pelo perfil do empreendedor, que procura por benefícios fiscais favoráveis com o objetivo de melhores margens de retorno, além da diferença na formação de preços para conquistar novos mercados, expandindo a possibilidade de levar seus negócios para outras regiões (Sebrae, 2020; Silva \& Rocha, 2001).

Entretanto, o exportador deveter cautela ao lidar com as regras dediferentes países, o que podeconjecturar como um desafio para as pequenas empresas. Neste caso, o empreendedor se depara com entraves que podem impedir a realização de negócios internacionais, como a excessiva burocracia, o custo da logística, a insegurança em relação à possibilidade do não recebimento das vendas (inadimplência), a fraca rede de relacionamentos, a falta de conhecimento em lidar com processos burocráticos e as dificuldades processuais por parte do empreendedor/administrador (Amal \& Raboch, 2008; Herrera, 2010; Mariotti, Borini, Santos \& Pereira, 2018).

Com o interesse em expandir e fortalecer a cultura do pequeno empreendedor no mercado externo, o governo oferece programas de incentivos às empresas interessadas na exportação que, embora tenham pouca representatividade na balança comercial, desempenham um importante papel para o crescimento social do país, pois contribuem para a criação de emprego e geração de renda para a população, segundo o Ministério da Indústria, Comércio Exterior e Serviços/MDIC (BRASIL, 2020)

Uma das ações de destaque do governo em apoio à exportação foi a criação, em 2003, da Agência Brasileira de Promoção de Exportações e Investimentos (Apex-Brasil), que oferece vários serviços para ajudar a empresa em sua inserção no mercado internacional. Entre eles, encontra-se o Programa de Qualificação

Revista ADMPG, Ponta Grossa, v. 11, e2118482, p. 1- 17, 2021. 
para Exportação (PEIEX), executado com parcerias com instituições de ensino e pesquisa, dentre outras.

Se de um lado pode ocorrer uma expansão nos negócios internacionais, por outro há desafios e dificuldades ao realizar a primeira exportação (Sebrae, 2018). Para Borges (2012), os desafios do pequeno exportador referem-se às barreiras externas relacionadas à infraestrutura, que é composta por saneamento, transporte, energia e telecomunicações.

Uma pesquisa com 45 empresas, realizada por Alcântara, Calegario, Carneiro e Buchbinder (2015), buscou avaliar suas limitações na participação dos programas de apoio, de promoção e de financiamento à exportação no estado de Minas Gerais. Foi identificado que mais de $60 \%$ não apresentam condições adequadas para usufruir dos programas de financiamento tais como: não estar em dia com as obrigações fiscais; possuir restrições no Cadastro Nacional de Pessoa Jurídica; não dispor de tempo hábil para se dedicar aos programas. Dessa forma, dificulta o acesso ao uso de incentivos externos oferecidos pelos governos.

Segundo Dornelas e Carneiro (2018), embora os programas de apoio contribuam para o crescimento das exportações, alguns deles não consideram o tamanho da empresa, a experiência na indústria e o mercado internacional, podendo ocorrer vieses de seleção. Os autores sugerem que esses tipos de programas trabalhem com uma equipe técnica mais heterogênea e veem nos projetos governamentais, como o PEIEX, a necessidade de um especialista em comércio exterior como também de um programa mais longo, que ofereça um apoio mais detalhado em todo o processo de exportação, de modo a melhor dimensionar as expectativas dos exportadores e a aumentar o poder de articulação dessas empresas frente ao mercado externo.

Gomes et al. (2010), ao analisarem 26 periódicos publicados entre 2000-2008 com o objetivo de interpretar a razão e importância da internacionalização de PMEs, verificaram que a maior parte dos respondentes trazia o modelo da escola de Uppsala como principal referência. Os tópicos mais citados foram a importância do capital social e as redes de relacionamentos.

Torrens, Amal e Tontini, (2014) procuraram identificar as determinantes de desempenho à luz da teoria de Uppsala, por meio de uma amostra com 84 PMEs. Foram apontadas dificuldades como os recursos organizacionais (apoio a lançamento de produtos para exportação, apoio em feiras internacionais e visitas ao mercado externo) e os recursos gerenciais (percepção de barreiras impostas pela reputação dos produtos brasileiros e conhecimento de atividades internacionais). Desta forma, a atuação das agências de apoio ajudaria na superação dessas dificuldades, pois, a partir do momento que as empresas adquirem conhecimento sobre o mercado externo, passariam a atuar com maior autonomia no processo de internacionalização.

A presente pesquisa justifica-se pelas demandas observadas na literatura acima explicitada. Frente aos dados, pode-se considerar que os estudos não foram suficientes para compreender de maneira robusta quais foram os desafios da primeira exportação para o micro e pequeno empreendedor, cuja empresa participa de programas de apoio. Segundo Amal et al. (2010), Costa (2017) e Mariotti et al. (2018), focar nos desafios deste segmento é necessário, pois existem oportunidades e vantagens na expansão dos negócios para outros países, tornando-os mais competitivos no contexto econômico internacional.

Diantedopanorama exposto, levanta-seo seguinte problema de pesquisa:quais são osdesafiosenfrentados por micro e pequenos empreendedores em sua primeira exportação? Visando responder esta questão, este trabalho tem como objetivo geral identificar os desafios das micro e pequenas empresas, segundo percepção do empreendedor participante do PEIEX-FECAP, ao realizar a sua primeira exportação. Os objetivos específicos são caracterizar as empresas participantes e verificar se há diferença dos desafios entre os setores de atuação.

Para tanto, após a introdução, efetua-se a fundamentação teórica, seguida dos métodos, do tratamento e análise dos dados, da discussão dos resultados e, por último, das considerações finais.

\section{FUNDAMENTAÇÃO TEÓRICA}

Nesta seção será apresentada a base teórico dessa pesquisa, como internacionalização das empresas, 
exportação, benefícios da exportação e desafios da exportação.

\subsection{INTERNACIONALIZAÇÃO DAS EMPRESAS}

Os estudos sobre o processo de internacionalização das empresas ganharam importância a partir da década de 70 com o trabalho realizado por Johanson e Wiedersheim-Paul (1975) que desenvolveram uma pesquisa sobre a Internacionalização de quatro empresas suecas. Nos anos seguintes, um estudo de Johanson e Vahlne (1977) apresentou um modelo de desenvolvimento de conhecimento e compromissos crescentes no mercado externo. Posteriormente, foram desenvolvidos outros trabalhos que ficaram conhecidos como a Escola de Uppsala.

A teoria de Uppsala busca entender os aspectos comportamentais dos tomadores de decisão em vez de realizar uma análise meramente econômica (Hilal \& Hemais, 2004). Neste modelo, o foco é a exploração do mercado externo, pois constrói dessa forma um envolvimento, fortalece a network, acumula conhecimento e gera uma nova cultura e comprometimento gradual do empreendedor de acordo com a intensificação do relacionamento (Forsgren, 2002).

Segundo Johanson e Vahlne (2009), a teoria de Uppsala defende o envolvimento gradual das empresas para países geograficamente próximos a partir da aprendizagem e da obtenção de conhecimento sobre estes mercados, expandindo gradativamente suas ações para países com culturas mais distantes. No modelo de Uppsala, reforça-se o conceito da distância psíquica, que opera diminuindo as diferenças entre os mercados, onde a abordagem comportamental e as competências sociais são necessárias para interagir com pessoas e conhecer diferentes realidades culturais, sociais e de adaptação.

A teoria destaca ainda as competências na comunicação, negociação, mobilização para mudança, sensibilidade cultural, flexibilidade, adaptabilidade, trabalho em equipe e por fim, a transferência de conhecimento entre as culturas dos diferentes países. No estudo, constatou-se a partir de observações com quatro empresas suecas, Sandvik, Atlas Copco, Facit e Volvo, em 1975, que estas se internacionalizavam com poucos investimentos e, gradualmente, tendiam a aumentar sua presença no exterior.

Compreende-se que, ao exportar, as empresas adquirem um diferencial de qualidade e competência, uma vez que precisam adequar seus produtos e processos. No entanto, é necessária a consciência de todos os riscos envolvidos na exportação (Czinkota,1994).

As pequenas empresas têm identificado o mercado internacional como uma alternativa atraente. Dessa forma, as MPEs buscam cada vez mais adquirir experiência e ganhar território global. Para tal, os gestores procuram aprimorar as tomadas de decisões estratégicas, aprofundar o conhecimento sobre um determinado país, ser mais ativo nas redes de relacionamento e aumentar as percepções gerenciais de risco de mercado, aprofundar o entendimento no processo de exportação, além de uma especial atenção quanto aos custos e lucros nos mercados externos (Czinkota,1994; Leonidou, 2004; Moreira, 2014).

\subsection{EXPORTAÇÃO}

A globalização das economias e mercados tem conduzido as empresas a adotarem a internacionalização como uma de suas estratégias, de modo a se manterem competitivas e assegurarem o seu crescimento e sobrevivência. A exportação é o modo mais simples e comum de entrada nos mercados externos, principalmente para o micro e pequeno empreendedor, pois implica um menor envolvimento financeiro e de recursos de acordo com o Ministério da Indústria, Comércio Exterior e Serviços/MDIC (BRASIL, 2020).

Andersson (2000) defende a teoria do empreendedorismo internacional e enfatiza que as principais teorias de internacionalização ignoram a influência do indivíduo empreendedor, o qual é crucial para o processo de internacionalização. Neste sentido, o foco da análise passa a ser o empreendedor, que explora as oportunidades e lança luz na estratégia de internacionalização da empresa, a partir de suas impressões do ambiente macro.

Dessa forma, a exportação deixa de ser somente uma questão de mudança de produção para outros mercados e passa a ser percebida mais como a exploração de potenciais relacionamentos além das fronteiras (Hilal \& Hemais, 2004; Johanson \& Mattsson, 1988). 
Entretanto é importante que o empreendedor saiba compreender e decidir como será o processo de entrada em um mercado externo, principalmente no caso da exportação, em que os produtos são fabricados no país de origem e, posteriormente, disponibilizados ao comprador estrangeiro em local e prazos estipulados por meio de contratos de compra e venda (Pigatto, Ribeiro, \& Negreti, 2016).

Para exportar, as empresas precisam estrategicamente decidir como será o controle que querem exercer sobre o processo de exportação. $\mathrm{O}$ tipo de exportação escolhido poderá ter um envolvimento direto, administrado pela própria empresa, ou indireto, por meio de intermediários (Grzybovaki, Ongaratto, \& Lopes, 2008), tal como discriminados na sequência.

A Exportação direta (ou por conta própria) ocorre quando o produtor/exportador é o responsável pelo faturamento do produto e pela exportação (Katsikea \& Morgan, 2002).

Observa-se que, na exportação direta, a empresa detém o fluxo dos processos de um modo geral. Embora mais ambiciosa, essa modalidade pode ser a mais lucrativa e propiciar um maior crescimento no mercado internacional (Alves, Farias, Barbieri, \& Carvalho, 2010).

Já a Exportação indireta ocorre quando a empresa vende seus produtos em mercados estrangeiros por meio de um intermediário (agente) estabelecido em seu próprio país. O intermediário pode ser uma empresa comercial exportadora, uma trading company ou simplesmente um corretor (Keegan, 1980).

\subsection{BenefíCIOS DA EXPoRTAÇÃO}

Ao exportar, o empreendedor busca aumentar seu fluxo de oportunidades no mercado internacional com o objetivo de aumentar seus lucros, oferecendo seus produtos/serviços a um mercado mais amplo (Kotler, 1994). Além das oportunidades já discutidas, é um momento para captar novos clientes. Sendo assim, cabe ao empreendedor minimizar os impactos negativos dessa expansão (Porter, 2004; Sekliuckiene, 2015). Para isso, o empreendedor escolhe qual é a melhor forma para ingressar no mercado internacional. Mesmo as pequenas empresas, que não operam em escala global, precisam tomar decisões estratégicas importantes ao iniciar no mercado exterior (Bateman \& Snell, 2009).

A decisão de exportar surge por meio da exploração de novas oportunidades estratégicas em busca de novos mercados e clientes, além da vontade de que a empresa seja próspera (Gonçalves, 2015). Exportar podeser uma forma de mitigar e diluir os riscos edificuldades encontradas no mercado local, comodeclínio nas vendas relacionadas ao mercado saturado, aumento de competição, mudança de comportamento dos clientes, inabilidade comercial e técnica em relacionar-se com o mercado (Cassano, Ribeiro, Galvão, Cesar, \& Panazzolo, 2016; Leonidou, 2004).

De acordo com Anagusko, Araki e Moser (2020), as MPEsapresentam dificuldades e falhas em implementar mecanismos de controle na sua gestão, o que estimula a busca por soluções. Para Ganotakis e Love (2012), as empresas que possuem uma gestão operacional eficiente possuem processos de manufatura bem definidos, têm maiores chances de exportar. Isso acaba gerando um estímulo à exportação, que pode ser potencializado se houver também o domínio do idioma do país alvo e das regras e exigências técnicas dos produtos exportados (Leonidou, 2004).

Uma outra forma de exportar é possuir produtos específicos, o que pode atrair a atenção dos clientes estrangeiros, criando uma vantagem competitiva sem requerer custos adicionais ou altos investimentos em Pesquisa e Desenvolvimento (P\&D). Para isso, o empreendedor precisa apresentar uma postura e engajamento no apoio de novas ideias, novos experimentos e processos criativos que resultem em novos produtos (Miller, 1983).

Da mesma forma, as ações comerciais das empresas no mercado internacional devem ser precedidas de uma cuidadosa estratégia de marketing, onde vários fatores podem estimular a exportação como, por exemplo, a marca, o preço competitivo, os produtos bem posicionados frente aos concorrentes, além de um sistema de suporte ao cliente eficiente (Leonidou, 2004).

Por outro lado, Fernandes e Correia (2013) defendem que o estímulo às ações de marketing é definido pelo comportamento dos seus consumidores. Assim, as empresas precisam ajustar os planos e estratégias de marketing considerando os fatores sociais, pessoais e psicológicos que influenciam seus clientes, 
principalmente os fatores de ordem cultural.

Por fim, o câmbio também pode ser um estímulo à exportação, uma vez que a depreciação da moeda local torna os preços de vendas externos mais atraentes (Chaney, 2016). Quando ocorre a desvalorização da moeda local, a empresa passa a se interessar pelo mercado global, uma vez que seus gastos (custos e despesas) são em reais e os recebíveis (receitas) são em outra moeda mais valorizada como o dólar, por exemplo. Dessa maneira, abre-se uma ampla possibilidade da empresa obter maiores margens e, consequentemente, resultados favoráveis (Leonidou, 2004).

\subsection{Desafios Da exportaÇão}

Entende-se que exportar pode ser uma vantagem para a empresa. Não obstante, estudos de Borges, (2012), Lumpkin e Dess, (1996), Mariotti et al. (2018) e Oliveira, (2010), constataram que muitas MPEs não estão preparadas para exportar devido à falta de conhecimento e falta de informação, além das dificuldades em compreender o mercado alvo.

Segundo Polis (2019), as Pequenas e Médias Empresas (PMEs) enfrentam diversas barreiras internas e externas. Em barreiras internas, destacam-se as informacionais, que se referem a dificuldade em identificar e contatar clientes potenciais de mercado externo para a exportação, além da falta de gestão por parte dos empreendedores em conseguir representantes comerciais experientes e confiáveis no mercado externo, fator esse que dificulta a internacionalização.

Ainda nesse ponto, há as barreiras gerenciais, devido à falta de tempo gerencial e pessoal pouco qualificado para lidar com o mercado internacional, pelo fato dos líderes e gestores possuírem inúmeras tarefas no seu dia a dia, na maioria das vezes limitados ao tamanho disponível dos recursos humanos, e a falta de inovação tecnológica, uma barreira de empreendedorismo.

Já às barreiras externas, encontram-se as políticas, econômicas e legais, cujo destaque aponta a instabilidade política nos mercados estrangeiros como sendo um obstáculo para a empresa exportar. Em relação as barreiras processuais e monetárias, a maior dificuldade está na comunicação com as empresas no exterior (estrutura) como fator impeditivo à internacionalização, além das dificuldades em realizar cobrança no exterior e por fim, a flutuação da taxa de câmbio. Já as barreiras socioculturais, a concorrência é mais agressiva na exportação, podendo inviabilizar a operação, além do idioma e as diferenças com religião, valores, costumes, atitudes, dentre outros.

De acordo com Crick (2007), o desafio em exportar está mais relacionado ao perfil do empreendedor que encontra dificuldades em identificar e contatar potenciais clientes no exterior, além de estabelecer acordos de representação com parceiros adequados para a distribuição nos mercados internacionais, cujo alinhamento e parceria nesse processo é fundamental.

Conforme com Pereira (2017), há um grande desafio em relação à exportação com restrições financeiras. As pesquisas apontaram que as Micro e Pequenas Empresas com o caixa mais equilibrado apresentam uma maior probabilidade de exportar do que as empresas que apresentam um caixa financeiro mais fragilizado.

Segundo Ayob (2015), a baixa lucratividade das empresas e a insuficiência de ativos acabam dificultando as concessões de créditos frente a mercado financeiro, causando um enfraquecimento no capital de giro. Por fim, o estudo sugere que os bancos forneçam às PMEs mais financiamentos ou facilitem os requisitos de aprovação de empréstimos na tentativa de aumentar a participação dessas empresas no mercado externo.

Para Tesfom e Lutz (2006), a maior dificuldade dos pequenos empreendedores está relacionada em compreender o processo burocrático em sua totalidade, reforçando que não é somente o governo que impõe regras e burocracias processuais. Essas também podem ser originadas em instituições privadas como bancos, agentes de transportes e cargas, companhias de seguros, entre outras. De acordo com Kahiya e Dean (2016), o que dificulta entender toda a burocracia é justamente a limitação do empreendedor em não conhecer profundamente o processo de exportação.

Ainda Tesfom e Lutz (2006) trazem como principal desafio, no processo de exportação, a divulgação da

Revista ADMPG, Ponta Grossa, v. 11, e2118482, p. 1- 17, 2021. 
marca internacionalmente, que está diretamente relacionado à pouca prática e à falta de conhecimento sobre o mercado de interesse. Esse desconhecimento sobre o posicionamento de marketing/marca no exterior muitas vezes impacta na competividade das empresas, uma vez que esta variável está vinculada aos produtos, preços, à distribuição logística e às promoções de acordo com o Conselho Nacional da Indústria (CNI) (2018). Nesse aspecto, a administração exerce um papel importante no desenvolvimento das estratégias relacionadas à exportação e na condução dos negócios com os clientes externos (Julian \& Ahmed, 2005). Já o estudo de Narayanan (2015) menciona que possuir conhecimento sobre os processos envolvidos na condução dos negócios no exterior é um requisito primordial para o sucesso de entrada das MPEs em mercados estrangeiros.

Outros fatores que dificultam a exportação estão relacionados a controlar os representantes, intermediários e a obter informações de acesso aos canais de distribuição (Tesfom \& Lutz, 2006; Sebrae, 2017). Por fim, a inadequação por parte dos funcionários, falta de comprometimento dos administradores/ empreendedores e carência dos conhecimentos dos funcionários sobre a condução dos negócios no exterior (Julian \& Ahmed, 2005; Leonidou, 2004; Narayanan, 2015).

\section{MÉTODO}

Nesta seção serão apresentados os procedimentos metodológicos utilizados para a investigação dos desafios da primeira exportação, destacando-se a abordagem metodológica e a estratégia de pesquisa desenvolvida.Para facilitar a compreensão, foi dividida em subseções: abordagem da pesquisa qualitativa, estudo exploratório, amostra, instrumento e procedimentos.

\subsection{Abordagem Da PESQUisa QUAlitativa}

Trata-se de uma pesquisa qualitativa, que, segundo Silva e Menezes (2001), busca por respostas para um determinado problema por meio de um conjunto de ações que têm por base procedimentos racionais e sistemáticos. Quando ocorre ausência de informação e existe um problema a ser resolvido, a pesquisa possibilita levantar soluções para esse problema.

Para Vieira (2004), a pesquisa qualitativa permite o levantamento de dados consistentes e diversos sobre uma amostra pequena, proporcionando a compreensão dos fatos da realidade social a partir de seu contexto. Glazier e Powell (2011) defendem que a melhor maneira de entender o que significa pesquisa qualitativa é definir o que ela não é, ou seja, ela não é um conjunto de procedimentos que depende de análise estatística para suas inferências ou de métodos quantitativos para a coleta de dados.

Segundo Gaskell (2002), a pesquisa qualitativa fornece dados básicos para o desenvolvimento e a compreensão das relações entre os atores sociais e sua situação.

\subsection{ESTUDO EXPLORATÓRIO}

Esse estudo classifica-se como exploratório, ou seja, tem como objetivo proporcionar maior familiaridade com o problema, com vistas a torná-lo mais explícito ou em construir hipóteses (Gil, 2010). Na pesquisa exploratória, o pesquisador dispõe de poucas informações a respeito do assunto e assim, trabalha para observar descobertas (Hair, Money, \& Samouel, 2005).

\subsection{Amostra}

A amostra se deu por conveniência, de modo que os entrevistados tiveram experiências práticas com o objeto de pesquisa escolhido (Flick, 2020; Yin, 2001). Como critério de inclusão, foram selecionadas empresas com interesse em exportar, participantes do PEIEX entre os anos de 2018 a 2020 e classificadas como Micro e Pequenas Empresas. De acordo com definição de porte estabelecida pelo Sebrae/Dieese, são aquelas que empregam até 9 colaboradores em caso de comércio e serviços ou até 19 em setores industriais ou de construção civil (Sebrae, 2018).

O PEIEX é um programa da Apex-Brasil, uma agência técnica do Ministério da Indústria, Comércio Exterior e Serviços (MDIC) que organiza várias iniciativas, visando promover as exportações das empresas brasileiras para o exterior com ações diversificadas de promoção de negócios e imagem por 
meio de rodadas de negócios, estratégias para internacionalização como o apoio à participação em feiras internacionais, visita de compradores estrangeiros e formadores de opiniões e qualificação empresarial ao micro, pequeno e médio empreendedor (Apex-Brasil, 2020).

Uma das iniciativas da Apex-Brasil é o PEIEX, executado pelo núcleo operacional por meio de parcerias com instituições locais de ensino e pesquisa, como universidades, parques tecnológicos, ou fundações de apoio à pesquisa. $\mathrm{O}$ atendimento é feito com visitas, cujo propósito é medir o potencial exportador das empresas e levantar informações para que seja então elaborado um plano de trabalho com os requisitos necessários à exportação (Apex-Brasil, 2020).

O PEIEX existe há 10 anos e já atendeu 23 mil empresas. Nos últimos cinco anos, foram mais de 11 mil empresas atendidas. Em 2019, o número de empresas chegou a quase 2 mil, por meio de parcerias com 35 núcleos de apoio, instalados em 22 estados brasileiros, chamados de "entidades executoras do programa", responsáveis pela aplicação da metodologia PEIEX na qualificação das empresas (Apex-Brasil, 2020).

Um dos núcleos instalados em São Paulo é o PEIEX-FECAP, projeto executado pela Fundação Escola de Comércio Álvares Penteado (FECAP) junto com a Apex-Brasil, parceria essa que tem por objetivo desenvolver ações para auxiliar empresas de pequeno e médio porte a atuarem para iniciar ou ampliar suas operações de comércio exterior.

Compuseram a amostra três empresas que participaram do PEIEX-FECAP entre os períodos de 2018 a 2020. Os entrevistados das empresas foram nomeados de E1, E2 e E3 para preservar o sigilo. Como representantes e sujeitos da pesquisa, tivemos o diretor de operações e comércio internacional da Empresa-1 e os diretores proprietários das Empresa-2 e Empresa-3, sendo que todos os representantes entrevistados participaram do PEIEX-FECAP.

A escolha das empresas em segmentos diversos visa buscar uma diversificação dos entrevistados com intuito de contribuir com a pesquisa. A Empresa-1, por exemplo, trabalha com fabricação de produtos diversos, com vendas exclusivas via e-commerce, a empresa buscou no PEIEX a formação para uma melhor gestão, além de melhorar os processos e a forma de comunicar-se com o mercado internacional.

Já a Empresa-2 atua com prestação de serviços em atividades de produção cinematográfica, porém necessitava de uma gestão mais focada, além de outras oportunidades de melhorias em processos, de modo a adequar-se a fornecedores internacionais e a entender o funcionamento do fluxo financeiro internacional.

Por fim a Empresa-3, que atua como indústria farmoquímicos desde 2005, buscou a ajuda do PEIEX para melhor entender do mercado de exportações. Um dos diferenciais dessa indústria é que ela possui produtos patenteados e exclusivos no mercado doméstico. A intenção dos dirigentes era levar esses produtos ao mercado internacional e disputar clientes principalmente no mercado americano, porém devido à dificuldade em renovar uma de suas licenças (vigilância sanitária), até o momento da entrevista a empresa não havia exportado.

\subsection{INSTRUMENTO}

Para a coleta de dados foi utilizada a entrevista semiestruturada. De acordo com Bleger (2011), neste modelo, o roteiro de perguntas é flexível e o entrevistado tem liberdade de resposta.

Devido à pandemia da Covid-19, a coleta de dados se deu por meio de entrevistas remotas. Segundo Lobe, Morgan e Koffman, (2020), trata-se de um método "socialmente distante" de coleta de dados. A comunicação baseada na Internet oferece muitas oportunidades e, portanto, é importante considerar quais serviços podem melhor atender às necessidades da pesquisa. Foi utilizada, durante as entrevistas, a ferramenta de vídeo conferência Zoom Meetings, escolha feita pela facilidade de uso, além de ser uma ferramenta popular e gratuita. Ademais, os entrevistados já possuíam o aplicativo instalado e configurado em seus equipamentos.

Assim, as entrevistas foram realizadas com ferramentas de videoconferência, devidamente gravadas com o consentimento de cada um dos entrevistados. Os nomes foram substituídos por letras e nenhuma informação pessoal foi divulgada a fim de garantir o sigilo dos participantes. 


\subsection{Procedimentos}

Foi enviada uma carta de apresentação e convite à pesquisa, junto ao questionário para 194 empresas participantes do programa de qualificação do PEIEX-FECAP, realizado entre 2018 a 2020. Destas, oito responderam ao questionário e três aceitaram participar das entrevistas, constituindo assim a amostra.

\section{TRATAMENTO E ANÁLISE DOS DADOS}

\subsection{DescriçÃo Das entrevistas}

Os resultados encontrados nas entrevistas permitem realizar algumas considerações. Para sistematizar a discussão, seguiremos com categorias definidas nessa pesquisa que são: Gestão, Processual, Marketing, Governo, Financeiro, Sociocultural, Infraestrutura e, final, a síntese das categorias e suas frequências.

\subsection{Categoria de gestão}

De acordo com Polis, (2019), Sebrae, (2017) e Tesfom e Lutz, (2006), a falta de gestão por parte dos empreendedores é vista por não conseguir representantes comerciais no exterior. Há a falta de tempo gerencial dos empreendedores das MPEs, além da inexperiência dos funcionários em lidar com o mercado internacional. Desafios da gestão foram identificados em todas as falas, corroborando com os autores. Essa categoria registrou uma frequência de (23) e, embora tenha equiparado com a processual, pôde ser percebido um certo incômodo nas falas dos entrevistados. Trechos como a E1 "[...] a responsabilidade do pagamento das taxas é do cliente, só que muitas vezes ele também não sabe, e a gente também não. Então, quando você trabalha com o cliente final no e-commerce, é muito mais complicado porquê pode acabar frustrando o consumidor final. Ele espera pagar um valor A e de repente aparece B, falta conhecimento, falta gestão". Já a E2 disse "[...] a gente tinha dificuldades com o planejamento". Por fim a E3 destacou: "Tivemos dificuldades para exportar na Europa, por não conhecer as regras [...]". Conclui a E3: "A gente tinha dificuldade em comunicar com o cliente, não tinha tempo hábil [...], " e "o que foi uma pedra no meu sapato foi a falta de conhecimento de exportação".

\subsection{Categoria processual}

Nota-sequea categoria processual,suafrequência(23) equiparou-secomacategoria degestão.TesfomeLutz (2006) e Sebrae (2017) argumentam que o desafio está em compreender o processo de internacionalização, o que se estende além das burocracias governamentais. Os excertos da E1 corroboram com os autores, pois apontam dificuldades: "Depois teve uma questão de não entender exatamente as documentações, como por exemplo a commercial invoice”. Já E2 contradiz a teoria de Chaney (2016) em relação à taxa do câmbio: "Na verdade, é complicado com essa desvalorização das nossas moedas [...], quando trabalho com parceiros em outros países a moeda influencia bastante". E3 destacou que "alguns países da Europa não se filiaram no GHS, [Sistema Globalmente Harmonizado de Classificação e Rotulagem de Produtos Químicos: grifo] você precisa tomar cuidado se for vender pra aquela região". Por fim, os processos de ordem financeira podem se tornar uma grande ameaça, conclui E3 "Se você está exportando, você não conhece o cliente, [...] como você vai conseguir analisar o crédito e entender os processos dessa empresa?”.

\subsection{Categoria marketing}

Os excertos dessa categoria extraídos das entrevistas transcorreram como desafios desde a questão da embalagem, além das informações que deviam conter nos produtos e material a ser utilizado. Foram citados nas entrevistas diversos desafios além dos produtos e embalagens, tais como, estrutura de apoio na pós-venda e dificuldades com a divulgação da marca. Porém foi percebido que os desafios foram superados, conforme foram surgindo as exportações. Confirma El, "Quando a gente pensou no produto, o desafio foi no material". Já sobre a falta de um setor de pós venda a mesma El relatou: “Tivemos muitas reclamações com os produtos, as embalagens chegavam danificadas [...]", ainda El: "Para exportar precisamos modificar nossos produtos. Isso foi um dos grandes desafios, fizemos uma primeira mudança na caixa do produto, deu tudo certo, além de trabalhar inicialmente com manuais em dois idiomas”. Já a E3 relatou muitas dificuldades, desafios e dúvidas na questão da divulgação da marca no exterior, disse: 
“Temos um produto que só a gente produz no Brasil, porém por não conhecer o mercado internacional, vem a pergunta: Onde é que vou colocar isso? Como é que eu consigo ter uma expansão das vendas fora do Brasil? Concluiu E3: "Nosso problema, quando pensamos em exportar, foi saber para quem exportar, quem vai consumir nossos produtos? Não sei. Então a gente teve que fazer a pesquisa literalmente do zero, em relação a isso, o PEIEX ajudou muito".

Sendo assim, os trechos corroboraram com as falas de (Fernandes \& Correia, 2013; Leonidou, 2007; Tesfom \& Lutz, 2006) sobre adequar a marca e produto ao mercado internacional, que pode se tornar uma dificuldade, assim como as ações comerciais precedidas com as estratégias de marketing e a adaptação dos produtos para que se adequem aos padrões do mercado.

\subsection{Categoria governo}

A instabilidade política nos mercados estrangeiros dificulta a exportação e traz um certo desconforto ao pequeno exportador, além do pouco apoio do governo local e da imagem país divulgada mundo afora, potencializando ainda mais os desafios para o empresário exportador. Esse tipo de desconforto pôde ser percebido nas entrevistas, como E2: "Hoje eu acho que existe uma pressão sim de exportar e de trabalhar com produções internacionais justamente por causa disso, porque a gente está com o nosso mercado cultural, nossa indústria cinematográfica que foi completamente tolhida pelo governo atual, que parou com os incentivos". Ainda a E2: "Precisa existir uma política de desenvolvimento da indústria, [...] não tem gestão, não tem cultura no Brasil, não tem indústria”. Ainda nas entrevistas a falta de apoio do governo pode ser percebido como relata a E3: "Tive dificuldades com suporte de órgãos do governo, por não conhecer. É importante você saber que existem órgãos para te dar suporte, porque eu percebo que muitas vezes esses órgãos se aproximam mais de empresa grandes e médias".

Tais barreiras e desafios foram identificadas em estudos anteriores, sendo que as falas corroboram com a teoria. Segundo Amal e Raboch, (2008), Herrera, (2010) e Mariotti et al. (2018), estes fatores são descritos como dificuldades de inserção das MPEs no mercado internacional, ocasionando perda de oportunidades e aumento da pressão mercadológica em exportar.

\subsection{CATEgoria FinANCEIRA}

Os excertos a seguir ilustram a categoria do financeiro, onde pôde ser clara a insegurança em relação à necessidade de capital de giro, como disse E3: "Uma das coisas que me preocupou muito foi o fluxo de caixa. Em alguns casos o recebimento das vendas chegava a ser de 120 dias". Porém excertos da E1 trazem uma outra perspectiva quanto à necessidade de capital de giro e insegurança quanto ao recebimento das vendas. Por utilizar outros meios de pagamento como o PayPal e explorar de forma criativa plataformas de financiamento coletivo como o Catarse, não foram identificados em sua fala desafios na ordem financeira. Deve-se enfatizar o inverso nessa entrevista, pois foi identificado que explorar recursos inovadores pode aliviar a volatilidade do fluxo de caixa financeiro, explicou El: "Quando a empresa pensou em exportar, começou com uma campanha de financiamento coletivo, ou seja, a empresa colocou o produto no site, no Catarse [...]", ainda El: “[...] porque a venda estava feita. Não tinha nem empresa ainda. O empreendedor fez a campanha visando juntar o dinheiro dessas pessoas que querem esse produto. Deu certo, aí ele abriu a empresa”, por fim, conclui El: "Quanto ao pagamento, não foi um problema muito grande porque foi simplificado pelo uso do PayPal”.

De acordo com Amal e Raboch, (2006) e Herrera, (2010), a insegurança em relação ao não recebimento das vendas, pode acarretar o aumento da inadimplência, devido à fraca rede de relacionamentos. Em contrapartida, outra teoria sustenta que a postura e engajamento do empreendedor em propor e apoiar novas ideias, novos experimentos e processos criativos podem atrair a atenção de novos clientes, criando dessa forma uma vantagem competitiva (Ayob, 2015; Miller, 1983; Pereira, 2017).

\subsection{Categoria sociocultural}

A categoria sociocultural pôde ser extraída nos excertos com trechos relacionados ao idioma, porém as entrevistas contradizem Ortiz et al. (2014), que trazem em seus estudos barreiras exógenas, referentes ao comportamento e cultura dos clientes e fornecedores no exterior. Em relação ao mercado, as empresas 
buscaram regiões distintas, conforme o segmento de atuação. El, por trabalhar com e-commerce, atende diversos países, tornando-a sua carteira de clientes mais diversificada, embora seja no mercado europeu que se concentra a maioria dos clientes. A E2, atua fortemente no mercado europeu, onde a França foi um dos locais de forte atuação (devido parcerias cinematográficas locais), por fim, a E3, que vislumbrava no continente americano uma boa oportunidade, até conhecer o potencial de vendas no mercado sulamericano, reforço aqui que a Argentina passa a ser um país de maior interesse comercial.

Os achados nas entrevistas trouxeram somente as barreiras do idioma e não foram identificadas outras barreiras culturais como religião, valores, costumes, atitudes, entre outras. Confirma E2: “Tivemos problemas com o idioma no início, porque a gente teve que se adequar e teve que passar a trabalhar com fornecedores lá de fora”. Também E3 confirmou: "Tive problema com o idioma, em falar outra língua, lembro que um dos vendedores, que é um dos mais antigos na empresa, ele ficou responsável comigo para fazer o atendimento e dar suporte para clientes e fornecedores lá fora, somente nós dois sabíamos falar inglês, isso acabou me sobrecarregando".

Por fim, foram encontradas implicações do conceito de "distância psíquica" defendidas por Johanson e Vahlne (2009), quanto maior a diferença entre o país de origem e o país estrangeiro em termos de desenvolvimento, nível e conteúdo educacional, idioma, cultura, sistema político, entre outros, maior o nível de incerteza, que se mostraram presentes na E3 como: "Por causa do idioma que a gente focou especialmente a Argentina e o Uruguai nesse primeiro momento dentro do Mercosul”.

\subsection{Categoria infraestrutura}

Na última categorização, intitulada de infraestrutura, extraem-se relatos das entrevistas El e E3 sobre os desafios em entender os processos de transporte, custos logísticos e trâmites documentais. E3 relatou: "Acontece que o produto tem uma classificação de risco alto, isso torna muito mais difícil, complexa e cara a exportação para Europa ou Estados Unidos [...]”, já a El disse: "A gente foi aprendendo aos poucos como que se dava esse processo de transporte, quais eram as documentações exigidas [...]”. Por fim, conclui El: "Tivemos problemas com a empresa exportadora, quer dizer, a logística, eles ajudam a gente um tanto, porém eu acredito que eles precisavam se preparar melhor para nos dar mais suporte”.

Os excertos corroboram com a teoria. Segundo Borges (2012), o desafio das MPEs refere-se às barreiras relacionadas a infraestrutura. Entretanto, não foram encontrados, nesse estudo. trechos sobre demais barreiras como saneamento, transporte, energia e telecomunicações. Para Tesfom e Lutz (2006), o desafio do empreendedor está em compreender todo o processo de exportação, incluído fornecedores e agentes de transporte.

\subsection{Categorias e suas FrequênCias}

A Tabela 1 sintetiza os desafios da primeira exportação, de acordo com categorização apresentada pela sua base teórica, através dos dados relativos à frequência de palavras, utilizando o software MAXQDA 2020.

Observa-se que as categorias mais citadas nas entrevistas foram os desafios com: Gestão (23), Processual (23), Marketing (20), Governo (10), Financeiro (6), Sociocultural (6) e Infraestrutura (4).

A importância da frequência na pesquisa qualitativa é identificar a presença ou ausência de determinado tema no conteúdo a ser analisado, para, então, poder compreender melhor como este se apresenta no texto e suas peculiaridades, dando a análise maior profundidade. 


\begin{tabular}{cc}
\hline Categorias & Freq. \\
\hline Gestão & 23 \\
Processual & 23 \\
Marketing & 20 \\
Governo & 10 \\
Financeiro & 6 \\
Sociocultural & 6 \\
Infraestrutura & 4 \\
\hline Total & $\mathbf{9 2}$ \\
\hline
\end{tabular}

Fonte: os autores

\section{DISCUSSÃO DOS RESULTADOS}

As amostras se caracterizaram por empresa El, cujo ramo de atividade principal está na fabricação de produtos diversos com vendas para o consumidor final (e-commerce), a empresa E2, que atua diretamente com prestação de serviços no mercado cinematográfico com criação de conteúdos para programas de televisão e, por fim, a empresa E3, que atua num setor altamente competitivo, fabricação de produtos farmoquímicos. Nas entrevistas, embora de segmentos diferentes listados acima, foram identificados o desafio da ordem de gestão e o de apoio ao governo, comuns às três participantes.

Entretanto as palavras gestão e processual tiveram maior frequência. Embora ambas tenham sido citadas na mesma proporção, detecta-se nas entrevistas uma inquietação por parte dos entrevistados das três empresas quando o assunto em discussão é gestão, categoria mais enfatizada devido a sua fragilidade por parte dos dirigentes como pouco conhecimento no processo de exportação, falta de tempo gerencial e equipe inexperientes, desafios que corroboraram a teoria.

Na segunda categoria, que é a processual, foram identificadas dificuldades em compreender os processos burocráticos governamentais e em entender os processos de cobrança no exterior, citadas em todas as entrevistas. Não obstante, a flutuação na taxa de câmbio, quando a necessidade em contratar parceiros no exterior, apareceu somente na E2.

Na terceira categoria, que é a de marketing, excertos corroboraram com a teoria, onde trechos como pouca divulgação da marca, falta de um setor estruturado de pós venda e adequação dos produtos no exterior como desafios foram identificadas nas E1 e E3. Na quarta categoria, que é governo, os trechos como instabilidade política nos mercados estrangeiros, pouco apoio governamental além do risco país e imagem do Brasil fragilizado puderam ser percebidos nas E2 e E3.

Na quinta categoria, a financeira, trechos como necessidade de capital de giro e obtenção de linhas de crédito não foram identificados na El em relação à insegurança aos recebimentos das vendas. Em compensação, explorar novos recursos tecnológicos corroboraram com a teoria em todas as empresas. Já a sexta categoria, a sociocultural, dificuldades em usar outro idioma foi um desafio encontrado em todas as entrevistas, porém barreiras exógenas e culturais não foram identificadas nas entrevistas.

Por fim, na última categoria, infraestrutura, custo logístico, trâmites documentais e serviços logísticos foram identificados nas E1 e E3. Já na E2 não se aplica desafio dessa ordem por ser uma empresa de prestação de serviços.

A Tabela 2 concentra as principais características de acordo com os desafios ora categorizados nesse estudo. 


\begin{tabular}{|c|c|c|c|c|}
\hline $\begin{array}{c}\text { Desafios por } \\
\text { Categoria } \\
\end{array}$ & Principais características & $\mathbf{E 1}$ & $\mathbf{E 2}$ & $\mathbf{E 3}$ \\
\hline \multirow{4}{*}{ GESTÃO } & Falta de Gestão & $\mathrm{X}$ & $\mathrm{X}$ & $\mathrm{x}$ \\
\hline & Funcionários Inexperientes & & & $\mathrm{X}$ \\
\hline & Não conhecer os processos de exportação & $\mathrm{X}$ & & \\
\hline & Falta de tempo Gerencial & & & $\mathrm{X}$ \\
\hline \multirow{4}{*}{ PROCESSUAL } & $\begin{array}{l}\text { Dificuldades em compreender os processos burocráticos } \\
\text { das entidades de classe }\end{array}$ & $\mathrm{X}$ & & $\mathrm{X}$ \\
\hline & Flutuação da taxa de câmbio & & $\mathrm{X}$ & \\
\hline & $\begin{array}{l}\text { Dificuldades em compreender os processos burocráticos } \\
\text { governamentais }\end{array}$ & & & $\mathrm{X}$ \\
\hline & Dificuldades em realizar a cobrança no exterior & & & $\mathrm{X}$ \\
\hline \multirow{3}{*}{ MARKETING } & Pouca divulgação da marca & $\mathrm{x}$ & & $\mathrm{X}$ \\
\hline & Falta de um setor de pós venda & $\mathrm{X}$ & & \\
\hline & Embalagem & $\mathrm{X}$ & & \\
\hline \multirow{2}{*}{ GOVERNO } & Pouco apoio do Governo & $\mathrm{X}$ & $\mathrm{X}$ & $\mathrm{X}$ \\
\hline & A imagem do Brasil afora & & & $\mathrm{X}$ \\
\hline \multirow{3}{*}{ FINANCEIRO } & Necessidade de Capital de Giro & $\mathrm{X}$ & & $\mathrm{X}$ \\
\hline & Concessão de Créditos & $\mathrm{X}$ & & \\
\hline & Insegurança em relação ao recebimento das vendas & $\mathrm{X}$ & & \\
\hline \multirow{2}{*}{ SOCIOCULTURAL } & Dificuldade em usar outro idioma & & $\mathrm{X}$ & $\mathrm{X}$ \\
\hline & Diferenças socioculturais & & $\mathrm{X}$ & $\mathrm{X}$ \\
\hline & Trâmites legais & $\mathrm{X}$ & & \\
\hline INFRAESTRUTURA & Serviços e parcerias logísticas & $\mathrm{X}$ & & \\
\hline Nota. X presente; - ausent & $\begin{array}{l}\text { Custo Logístico } \\
\text { te. }\end{array}$ & & & $\mathrm{X}$ \\
\hline
\end{tabular}

Fonte: os autores

\section{CONSIDERAÇÕES FINAIS}

Esta pesquisa teve como objetivo identificar os desafios das MPEs ao realizar a primeira exportação. A amostra se deu através das empresas que participaram do programa de qualificação do PEIEX-FECAP entre os períodos de 2018 a 2020. Na metodologia optou-se por abordagem qualitativa, por meio de entrevistas semiestruturadas. As empresas da amostra representam setores diferentes de atuação indústria com foco no consumidor final, outra de serviços e a última farmoquímicos.

De uma forma geral, os principais desafios para a primeira exportação, segundo a percepção dos empreendedores, relacionam-se à gestão, como dificuldades de planejamento, falta de experiência internacional do gestor e equipe pouco qualificada. Em seguida o desafio de ordem processual, como dificuldades em compreender os processos burocráticos das entidades de classe, além das dificuldades em compreender a flutuação da taxa de câmbio. Na sequência vem o marketing, cujos excertos registrados estão na ordem de desafios em estruturar a pós venda, adaptar as embalagens e produtos (como manual 
técnico), além da pouca divulgação da marca no exterior.

Os resultados obtidos corroboram com a literatura atual sobre as micro e pequenas empresas e demonstram a importância do empreendedor buscar qualificação e capacitação, além de reforçar o comprometimento da sua equipe em compreender os processos internacionais. Constatou-se ainda o desafio em melhor negociar com representantes e intermediários comerciais, buscar conhecer o mercado alvo, além de uma especial atenção ao caixa financeiro. Este ponto poderia ser explorado através de políticas públicas ou programas de qualificação à exportação como o PEIEX, oferecido para as MPEs por meio da Apex-Brasil.

Em relação aos desafios financeiros, uma contribuição pode ser a busca de novas tecnologias disponíveis, como o meio de pagamentos do tipo PayPal ou mesmo a plataforma de financiamento coletivo da Catarse, que fomenta, potencializa e legitima a presença de tecnologias a serviços das MPEs, elucidando que a disposição de uma boa estratégia com o uso de novas tecnologias pode contribuir com a consolidação do caixa financeiro da empresa (Julian \& Ahmed, 2005).

Por fim, foi identificado que todos exaltaram o importante papel do PEIEX como meio de apoio e qualificação ao exportador, trazendo contribuições diretas para o negócio. Isso faz com que as MPEs possam explorar mais os mercados internacionais, ofertando produtos e serviços Made in Brazil.

Como limitação, esta dissertação teve uma amostra pequena, ocasionada pela baixa taxa de retorno das empresas dispostas a participar da pesquisa. Acredita-se que a atenção a esse item possa contribuir com pesquisas futuras e que o delineamento metodológico proposto complemente os estudos atuais sobre o tema.

Para estudos futuros, recomenda-se trabalhar com o tamanho da amostra maior, além de utilizar pesquisas quantitativas com modelos de regressão linear na projeção de resultados, com objetivo de avaliar o comportamento econômico das MPEs que participaram dos programas de qualificação contra as que não fizeram uso. Dessa forma, poderá se comparar empreendedores que atuam em setores diferentes, além de obter uma avaliação das empresas qualificadas. Isso contribuirá na identificação de seus resultados financeiros, além de sua expansão comercial frente ao mercado externo.

\section{REFERÊNCIAS}

Alcântara, J. N., Calegario, C. L. L., Carneiro, J. M. T., \& Buchbinder, F. (2015). Fatores determinantes da utilização de programas de apoio à exportação: Evidências de PMEs do Estado de Minas Gerais (MG). Revista de Administração Faces Jornal, 14(3), 114-132.

Alves G., Farias S., Barbieri G. L., \& Carvalho, D. T., de (2010). Redes inter-organizacionais de cooperação para a internacionalização. REGE Revista de Gestão17(2), 209-224.

Amal, M., \& Raboch, H. (2008). A Internacionalização de pequenas empresas: Um estudo de caso na região do vale do Itajaí (RS). Dynamis Revista Tecno-Científica, 14(1), 01-11.

Anagusko, L. H., Araki, M. E., \& Moser, E. M. (2020). Implantação da controladoria em micro e pequenas empresas no Brasil. O que considerar? Revista da Micro e Pequena Empresa (RMPE),14(1), 59-78.

Andersson, S. (2000). The internationalization of the firm from an entrepreneurial perspective. International Studies of Management \& Organization, 30(1), 63-92.

Apex-Brasil (2020). Agência brasileira de promoção de exportações e investimentos. Recuperado de www. apexbrasil.com.br

Ayob, Abu H. (2015). Financial factors and export Beauvoir of small and medium-sized enterprises in an emerging economy. Journal of International Entrepreneurship, 13, 49-66.

Bateman, T. S, \& Snell, S. A. (2009). Administração: Novo cenário competitivo (2a ed.). São Paulo: Atlas.

Bleger, J. (2011). Temas de Psicologia: Entrevista e grupos (4a. ed.). Tradução Rita Maria M. de Moraes. São Paulo: Martins Fontes. 
Borges, J. T. (2012). Financiamento ao comércio exterior: O que uma empresa precisa saber. Curitiba: Inter Saberes.

BRASIL, Ministério do Desenvolvimento, Indústria e Comércio Exterior. Estatística de comércio exterior. Brasília, 2020. Disponível em https:/www.mdic.gov.br/index.php/comercio-exterior/estatisticas-decomercio-exterior, recuperado em 07 de julho, 2020.

Cassano, F. A., Ribeiro, J., Galvão, K. P., Cesar, F. L., \& Panazzolo, M. R. (2016). Transferência tecnológica para ampliação de oportunidades de negócios internacionais: Caso Enrolls. Revista Eletrônica de Estratégia \& Negócios, 9(1), 152-179.

Chaney, T. (2016). Liquidity constrained exporters. Journal of Economic Dynamics and Control, 72(1), 141154.

Confederação Nacional da Indústria (2020). Catálogo de exportadores brasileiros. Recuperado de: http:// www.brazil4export.com

Confederação Nacional da Indústria (2018). Pesquisa CNI/FGV:Desafiosà competitividade das exportações brasileiras. Recuperado de: http://www.portaldaindustria.com.br/cni/canais/assuntos-Internacionais/ publicacoes/desafios-a-competitividade-das-exportacoes-brasileiras, de 07 de julho de 2020.

Costa, M. A. C. (2017). Internacionalização das empresas: Perspectivas, Motivações e Barreiras (Trabalho de Conclusão de Curso). Universidade Federal da Paraíba, PB, Brasil.

Crick, D. (2007). SME's' Barriers towards internationalization and assistance requirements in the (UK): differences between exporters and firms employing multiple modes of market entry. Journal of Small Business \& Entrepreneurship, 20(3), 233-244.

Czinkota, M. R. (1994). The world trade organization: Perspectives and prospects. Journal of international Marketing, 3(1), 85-92.

Davidson, W., \& Harrigan, R. (1977). Decisões-chave em Marketing internacional: Introdução de novos produtos no exterior. The Columbia Journal of World Business, Nova York, Columbia School of Business, 20(3), 11-12.

Dornelas, B. F.; Carneiro, J.M.T. (2018). Avaliação de perspectiva de programas de apoio à exportação: o caso do PEIEX da APEX-BRASIL. Revista Ibero-Americana de Estratégia - RIAE , 17(2), 50-61.

Faria, L. A., \& Simeone, J. G. (2019). Internacionalização de micro e pequenas empresas brasileiras: Análise exploratória da atividade de exportação. Núcleos, 16(2), 1-12.

Fernandes, P., \& Correia, L. (2013). Atitudes do consumidor em relação às práticas do marketing em Portugal. Tourism \& Management Studies, 9, 86-92.

Flick, U. (2020). An introduction to qualitative research. Universidad Distrital Francisco José de Caldas. Gôndola, Enseñanza y Aprendizaje de las Ciencias, 15(1), 171-175.

Forsgren, M. (2002). O conceito de aprendizagem no modelo do processo internacionalização Uppsala: Uma vista crítica. International Business Review, 11(3), 257-278.

Ganotakis, P., \& Love, J. H. (2012). Export propensity, export intensity and performance: The role of the entrepreneurial team. Journal of International Business Studies, 43(8), 693-718.

Gaskell, G. (2002). Entrevistas individuais e grupais. In: M. W. Bauer, \& G. Gaskell (Orgs.). Pesquisa qualitativa com texto, imagem e som: Um manual prático (pp. 64-89). Petrópolis: Vozes.

Gil, A. (2010). Como elaborar projetos de pesquisa (8a ed.). São Paulo: Atlas.

Glazier, J. D., \& Powell, R. R. (2011). Qualitative research in information management. Englewood: Libraries Unlimited.

Gomes, G., Silveira, A., \& Amal, M. (2010). Internacionalização de pequenas e médias empresas em periódicos de administração com alto fator de impacto: 2000-2008. Revista Ibero-Americana de Estratégia, $9(3), 112-138$. 
Gonçalves, M. R. B. (2015). A internacionalização de uma PME num mercado de nicho: O caso Ballet Rosa (EUA e Canadá) (Dissertação de Mestrado - Relatório de Estágio em Negócios Internacionais). Universidade do Minho, Braga, Portugal. Recuperado de http://hdl.handle.net/1822/37645

Grzybovaki, D., Ongaratto, A. P., \& Lopes, F. D. (2008). Estratégias de entrada das empresas do setor de cosméticos: Caso Região Sul do Brasil. In: B. K. Costa, \& M. I. R de. Almeida (Orgs.). Estratégia contemporânea: Internacionalização, cenários e redes, (pp. 44-67). Campinas, SP: Akademica.

Hair, J., Babin, B., Money, A., \& Samouel, P. (2005). Fundamentos de métodos de pesquisa em administração. Tradução Lene. Porto Alegre: Bookman.

Herrera, W. R. S. (2010). O desafio exportador - Dificuldades de inserção de micros e pequenas empresas Porto-Alegrenses no comércio internacional (Trabalho de Conclusão de Curso). Universidade Federal do Rio Grande do Sul, Porto Alegre, RS, Brasil.

Hilal, A., \& Hemais, C. A. (2004). O processo de internacionalização na ótica da escola Nórdica: Evidências empíricas em empresas brasileiras. Revista de Administração Contemporânea, 7(1), 109-24.

Johanson, J., \& Mattsson, L. (1988). Internationalization in industrial systems: A network approach. In: H. Hood, \& J. Vahlne (Eds.). Strategies in foreign competition (pp. 303-321). London: Croom Helm.

Johanson, J., \& Vahlne, J. E. (1977). The internationalization process of the firm-A model of knowledge development and increasing foreign market commitments. Journal of International Business Studies, 8 , 23-32. https://doi.org/10.1057/palgrave.jibs.8490676

Johanson, J., \& Vahlne, J. (2009). The Uppsala internationalization process model revisited from liability of foreignness to liability of outsider ship. Journal of International Business Studies, 40(9), 1411-1431.

Johanson, J., \& Wiedersheim-Paul, F. (1975). The Internationalization of the Firm: Four Swedish cases. Journal of Management Studies, 12, 305-322.

Julian, C., \& Ahmed Z. U. (2005). The impact of barriers to export on export marketing performance. Journal of Global Marketing, 19(1).71-94. Recuperado de http://www.haworthpress.com/web/JGM. doi:10.1300/J042v19n01_05

Kahiya, E. T., \& Dean, D. L. (2016). Export stages and export barriers: Revisiting traditional export development. Thunderbird International Business Review, 58(1), 75-89.

Katsikea, E., \& Morgan, R. E. (2002). Exploring export sales management practices in small-and mediumsized firms. Industrial Marketing Management, 32(6), 467-480.

Keegan, W. J. (1980). Multinational marketing management. College of Business and Economics. University of Delaware, 28(4), 4-14.

Kotler, P. (1994). Administração de marketing: Análise, planejamento, implementação e controle. São Paulo: Atlas.

Leonidou, L. C. (2004). An analysis of the barriers hindering small business export development. Journal of Small Business Management, 42(3), 279-302.

Lobe, B., Morgan, D.\& Hoffaman, K. A. (2020). Dados qualitativos: A era do distanciamento social. International Journal of Qualitative Methods, 19, 1-8.

Lumpkin, G. T., \& Dess, G. G. (1996). Clarifying the entrepreneurial orientation construct and linking it to performance. Academic of Management Review, 21(1), 135-172.

Mariotti, D. C, Borini, F. M., Santos, L. L, \& Pereira, R. M. (2018). A baixa internacionalização das empresas brasileiras: Uma análise das principais barreiras institucionais. RASI, 4(2). doi: https://doi.org/10.20401/ rasi.4.2.178

Miller, D. (1983). The correlates of entrepreneurship in three types of firms. Management Science, 29(7), 770-791.

Moreira, T. M. S. (2014). Dificuldades encontradas no processo de internacionalização: Estudo nas PME de 
mobiliário nos concelhos de Paços de Ferreira e Paredes (Dissertação de Mestrado). Instituto Politécnico Porto Alegre - RS, Brasil.

Narayanan, V. (2015). Export barriers for small and medium-sized enterprises: A literature review based on Leonidou Model. Entrepreneurial Business and Economics Review, 3(2), 105-123.

Oliveira, M, M., Jr. (2010). Multinacionais brasileiras: Internacionalização, inovação e estratégia global. Porto Alegre: Bookman

Ortiz, J. A., Ortiz, F. R., \& Emeterio, M. C. S. (2014). Las PYMES españolas em Latino América: Barreras a la exportación. Escuela de Administration de la Universidad EAFIT, 24, 53-78.

Pereira, C. M.V. (2017). Barreiras financeiras à exportação das PME: O caso da indústria do calçado (Dissertação de Mestrado). Universidade of Minho, Portugal.

Pigatto, G., Ribeiro, B. C. S, \& Negreti, A. S. (2016). Inserção no mercado internacional: Análise do comportamento das exportações das empresas alimentícias da Região de Marília/SP. E\&G Economia e Gestão, Belo Horizonte, 16(43), 126-151.

Polis, M. C. B. (2019). Barreiras à internacionalização de pequenas e médias (Dissertação de Mestrado). Universidade Estadual de Campinas, Faculdade de Ciências Aplicadas, Limeira, SP, Brasil.

Porter, M. E. (2004). Estratégia competitiva: Técnicas para análise de indústrias e da concorrência (2a ed.). Rio de Janeiro: Campus.

Sallenave, J. P. (1977). Pour une stratégie de développement international de l'enterprise. Direction et Gestion des Enterprises,' Paris, Institut National de Gestion Prévisionnelle et de Controle de Gestion, 13(4), $33-42$.

Sekliuckiene, J. (2015). International entrepreneurship: Linking entrepreneurial motivation, orientation, and network relationship. Amfiteatru Economic, 17(38), 327-341.

Silva, E. L., \& Menezes, E. M. (2001). Metodologia da pesquisa e elaboração de dissertação. Florianopolis: UFSC.

Silva, P. A., \& Rocha, A. da, (2001). Perception of export barriers to Mercosur by Brazilian firms. International Marketing Review, 18(6), 589-611.

Serviço Brasileiro de Apoio às Micro e Pequenas Empresas. (2017). Relatório da feira do empreendedor. São Paulo: Autor. Recuperado de https:/issuu.com/sebraesp/docs/relatorio_edicao_2017

Serviço Brasileiro de Apoio às Micro e Pequenas Empresas. (2018). As micro e pequenas empresas na exportação brasileira. Estados: 2009-2017, Brasília: Autor. Recuperado de https://bibliotecas.sebrae.com. br/chronus/ARQUIVOS_CHRONUS/bds/bds.nsf/d639276722716a4lc685la620e5e2e3d/\$File/19214.pdf

Serviço Brasileiro de Apoioàs Microe Pequenas Empresas. (2020). Atualização de estudo sobre participação de micro e pequenas empresas na economia nacional. Brasília: Autor.

Tesfom, G., \& Lutz, C. (2006). A classification of export marketing problems of small and medium size manufacturing firms in developing countries. International Journal of Emerging Markets, 1(3), 262-281.

Tookey, D. (1975). Exportar decisões de Marketing. Middlesex, Eng., Penguin Education.

Torrens, E.W., Amal, M., \& Tontini G. (2014). Determinantes do desempenho exportador de pequenas e médias empresas manufatureiras brasileiras sob a perspectiva da visão baseada em recursos e do modelo de Uppsala. Revista Brasileira de Gestão de Negócios, 16(53), 511-539. doi: 10.7819/rbgn.vl6i53.1601.

Vieira, M. (2004). Por uma boa pesquisa (Qualitativa em Administração). In D. Zouain, \& M. Vieira. (Orgs). Pesquisa Qualitativa em Administração (pp.13-28). São Paulo: Editora FGV.

Yin, R. (2001). Estudo de caso: Planejamento e métodos. Porto Alegre: Bookman.

Recebido em: 19/07/2021

Aceito em: 03/08/2021

Publicado em: 01/09/2021

Revista ADMPG, Ponta Grossa, v. 11, e2118482, p. 1- 17, 2021. 